\title{
Necrose Digital em Paciente com Lúpus Eritematoso Sistêmico e Esclerose Sistêmica Tratada com Inibidores da Fosfodiesterase
}

\section{Digital Necrosis Treated with Phosphodiesterase Inhibitors in a Patient with Connective Tissue Disease}

\author{
Lílian Scussel Lonzetti(1), Filipe Dari Krüger ${ }^{(2)}$, Paola Morandi( ${ }^{(3)}$, \\ Maria Lúcia Lemos Lopes ${ }^{(1,4)}$, Tatiana Freitas Tourinho ${ }^{(1,4)}$
}

\begin{abstract}
RESUMO
Os inibidores da fosfodiesterase têm sido introduzidos, nos últimos anos, como novos agentes farmacológicos no tratamento dos pacientes com fenômeno de Raynaud e isquemia digital. Será descrito o caso de uma paciente com lúpus eritematoso sistêmico e esclerose sistêmica limitada apresentando fenômeno de Raynaud grave e necrose digital refratária à terapia. A paciente obteve excelente resposta à associação de imunossupressão e sildenafil.
\end{abstract}

Palavras-chave: fenômeno de Raynaud, necrose digital, sildenafil, lúpus eritematoso sistêmico, esclerose sistêmica.

\section{INTRODUÇÃO}

A vasculopatia com isquemia e necrose de dígitos em pacientes com lúpus eritematoso sistêmico (LES) ou esclerose sistêmica (ES), é muitas vezes de difícil tratamento. Novos fármacos com ação vasodilatadora existem, alguns já disponíveis no Brasil. Será descrito o caso de uma paciente com necrose digital, com sintomatologia muito dolorosa, na qual se obteve resolução total das lesões e do quadro álgico após o uso de sildenafil.

\section{RELATO DE CASO}

Paciente com 45 anos, sexo feminino, branca, natural e procedente de Porto Alegre. Em maio de 2005, foi atendida na unidade de emergência da Irmandade Santa Casa de Misericórdia de Porto Alegre com dor intensa nos dedos em virtude de lesões necróticas em polpas digitais do

\begin{abstract}
The phosphodiesterase inhibitors have been used recently for the treatment of Raynaud's phenomenon and digital ischaemia. We report the case of a patient affected by systemic lupus erythematosus and limited systemic sclerosis who presented severe Raynaud's phenomenon with digital necrosis despite treatment. The patient presented an excellent response to the association of immunosuppressant therapy and sildenafil.
\end{abstract}

Keywords: Raynaud, digital necrosis, sildenafil, systemic lupus erythematosus, systemic sclerosis.

$1^{\circ}, 3^{\circ}, 4^{\circ}$ e $5^{\circ}$ dedos da mão esquerda e $2^{\circ}, 3^{\circ}, 4^{\circ}$ e $5^{\circ}$ dedos da mão direita que, não obstante o tratamento com bloqueador de canal do cálcio e inibidor da enzima de conversão da angiotensina em doses plenas, não apresentavam melhora. Referia que aos 37 anos passara a apresentar fenômeno de Raynaud trifásico e isquemia em polpas digitais, sendo acompanhada em ambulatório de reumatologia de um hospital universitário. Na evolução da doença, relatava eritema malar, fotossensibilidade e poliartrite simétrica, principalmente nas mãos, nos joelhos e nos cotovelos. Nessa ocasião apresentava critérios para classificação de LES: poliartrite, linfopenia, FAN positivo, fotossensibilidade e eritema malar. Fora iniciado o tratamento com difosfato de cloroquina $250 \mathrm{mg} /$ dia, nifedipina retard $20 \mathrm{mg}$ de $8 / 8$ horas, omeprazol $20 \mathrm{mg} / \mathrm{dia}$, e eventuais cursos de prednisona oral. Há quatro anos referia piora na duração e na freqüência do fenômeno de Raynaud observado nas

Recebido em 11/3/2008. Aprovado, após revisão, em 8/8/2008. Declaramos a inexistência de conflitos de interesse

Complexo Hospitalar da Santa Casa de Misericórdia de Porto Alegre. Santa Casa de Porto Alegre - Serviço de Reumatologia

1. Médica reumatologista.

2. Graduando de Medicina.

3. Médica internista.

4. Professoras da disciplina de Reumatologia da Universidade Federal de Ciências da Saúde de Porto Alegre (UFCSPA).

Endereço para correspondência: Lílian Scussel Lonzetti, Av. José Bonifácio 741, sala 506, Farroupilha, 90040-130, Porto Alegre-RS, e-mail: lilianlonzetti@hotmail.com 
mãos, com crises de cianose intensa seguidas por hiperemia nos dedos, referia também o espessamento da pele dos dígitos, caracterizando esclerodactilia.

Foi internada para analgesia com morfina. Apresentava anemia (Hb: $9 \mathrm{~g} / \mathrm{dL}$ ), aumento do VHS $(50 \mathrm{~mm} / \mathrm{h})$, linfopenia (linfócitos: $\left.622 / \mathrm{mm}^{3}\right)$, proteinúria $(0,4 \mathrm{~g} / \mathrm{L}$ ), complemento baixo (C3:82 UI), hipergamaglobulinemia $(2,9 \mathrm{~g} / \mathrm{d})$, anticorpo antinuclear positivo padrão nuclear pontilhado fino 1:5120 e anti-DNA não-reagente. Trazia exames antigos realizados entre os anos de 2001 e 2004, com anticorpo antinuclear positivo em título 1:1280 padrão pontilhado grosso anti-DNA 1:20, anti-RNP reagente, anti-SSA, anti-SSB, anti-Sm e anti-SCl-70 não reagentes. Com diagnóstico de lúpus eritematoso sistêmico e esclerose sistêmica na forma limitada, apresentando vasculopatia com necrose de polpas digitais, foi iniciada pulsoterapia endovenosa com metilprednisolona $1 \mathrm{~g} /$ dia por 3 dias consecutivos associado a ciclofosfamida $1 \mathrm{~g}$ no terceiro dia, além de manter a terapia prévia com bloqueador de canal do cálcio e inibidor da ECA. Após a pulsoterapia foi mantido uso diário de prednisona $20 \mathrm{mg}$, hidroxicloroquina 400 $\mathrm{mg} /$ dia, varfarina $2,5 \mathrm{mg} /$ dia, amitriptilina $25 \mathrm{mg} /$ dia, omeprazol $20 \mathrm{mg} /$ dia, carbonato de cálcio $500 \mathrm{mg} 2 \times /$ dia e vitamina D $800 \mathrm{U} /$ dia, e codeína + paracetamol $4 \times /$ dia e morfina.

Após seis pulsos mensais de ciclofosfamida, não obstante a melhora parcial das lesões e da perfusão, persistia a dor intensa, havendo necessidade de uso contínuo de morfina, em nível hospitalar. Foi, então, associado sildenafil, com aumento gradual da dose até $150 \mathrm{mg} /$ dia, por sete dias. A partir do quarto dia de tratamento, observou-se melhora da dor e da perfusão dos dedos, com cicatrização progressiva das úlceras necróticas, cessando a necessidade de analgesia com opióides. A anticoagulação foi substituída por ácido acetil salicílico $100 \mathrm{mg} /$ dia e a paciente completou doze pulsos de ciclofosfamida mensal. A paciente vem se mantendo estável, sem novas lesões isquêmicas ou necróticas desde 2005, e atualmente está em uso de azatrioprina 100 $\mathrm{mg} /$ dia e hidroxicloroquina $400 \mathrm{mg} /$ dia. No inverno, foi associado anlodipino $5 \mathrm{mg} /$ dia para tratamento do fenômeno de Raynaud.

\section{DISCUSSÃO}

No presente caso, observa-se a excelente resposta da vasculopatia ao sildenafil. No manejo da paciente, a associação de imunossupressão, de diversos vasodilatadores e de anticoagulação foram utilizados. Alterações no sistema autonômico já se encontram presentes em fases iniciais na esclerose sistêmica e a regulação do tônus vascular com pulsos de ciclofosfamida é descrita na literatura ${ }^{(1)}$. O uso de anticoagulação foi indicado, neste caso, pela necrose isquêmica refratária ao tratamento.

Em maio de 2005, quando foi usado o sildenafil, não havia experiência no nosso Brasil com esta droga. Por causa do grande sofrimento da paciente, foram usadas todas as medicações disponíveis e o sildenafil como última alternativa.

As terapias farmacológicas utilizadas para o tratamento de úlceras isquêmicas causadas pela vasculopatia relacionada a danos estruturais nos vasos sangüíneos associados ao fenômeno de Raynaud secundário muitas vezes têm resultados ineficazes. A boa resposta e a resolução das úlceras após a associação de sildenafil, um inibidor da fosfodiesterase, aponta esta classe de fármacos como drogas emergentes no tratamento de úlceras digitais com evolução para necrose de polpas digitais em doenças em que há associação de diversos mecanismos de lesão, como no caso descrito.

Diversos fármacos vêm sendo utilizados para o tratamento de úlceras isquêmicas causadas pelo fenômeno de Raynaud. As principais drogas empregadas, até o momento, foram os vasodilatadores (bloqueadores dos canais de cálcio, bloqueadores adrenérgicos e inibidores do receptor de angiotensina II $)^{(2)}$.

Os inibidores da fosfodiesterase, especialmente o sildenafil, têm sido introduzidos nos últimos anos como agentes farmacológicos eficientes no tratamento de úlceras distais.

Um estudo clínico randomizado, duplo-cego, controlado com placebo, demonstrou a eficácia e a boa tolerabilidade do sildenafil no tratamento do fenômeno de Raynaud resistente a outras terapias vasodilatadoras, diminuindo a freqüência das crises e o tempo de duração ${ }^{(3)}$. Uma revisão dos estudos publicados entre 1980 e 2006 também confirmou a efetividade clínica dos inibidores da fosfodiesterase em aumentar o fluxo sangüíneo nas lesões e na melhora das úlceras digitais, especialmente com o uso do sildenafil em comparação aos outros fármacos do grupo ${ }^{(4)}$. Há outros relatos de casos de pacientes com doenças auto-imunes, fenômeno de Raynaud e isquemia digital com bons resultados ao sildenafil ${ }^{(5)}$.

Pela baixa incidência de efeitos colaterais e por seus bons resultados clínicos nos pacientes com úlceras digitais isquêmicas, o sildenafil parece ser um fármaco promissor no tratamento dos pacientes com fenômeno de Raynaud e vasculopatias associadas. 


\section{REFERÊNCIAS}

1. Casale R, Generini S, Luppi F, et al.: Pulse cyclophosphamide descreases sympathetic postganglionic activity, controls alveolitis, and normalizes vascular tone dysfunction (Raynaud's phenomenon) in a case of early systemic sclerosis. Arthritis Rheum. 51: 665-9, 2004.

2. Sunderkötter C, Riemekasten G: Vasoactive therapies in systemic sclerosis. Rheumatology 4: 49-51, 2006.
3. Fries R, Shariat K, von Wilmowsky H, Böhm M: Sildenafil in the treatment of Raynaud's phenomenon resistant to vasodilatory therapy. Circulation 112: 2980-5, 2005.

4. Levien TL: Phosphodiesterase inhibitors in Raynaud's phenomenon. Ann Pharmacother 40: 1388-93, 2006.

5. Kumana CR, Cheung GTY, Lau CS: Severe digital ischaemia treated with phosphodiesterase inhibitors. Ann Rheum Dis 63: 1522-4, 2004 